
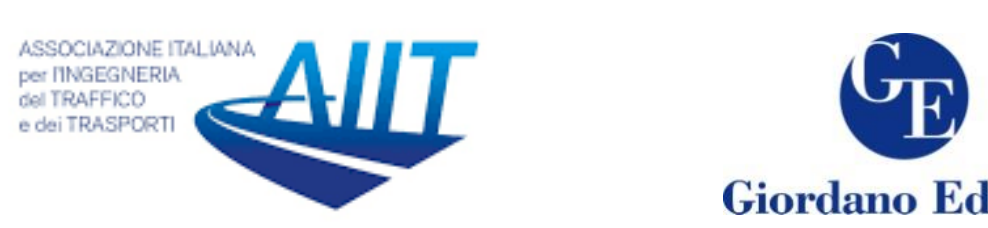

Giordano Editore

\title{
Transport infrastructure and systems in a changing world: towards a safer mobility
}

\author{
Matteo Ignaccolo ${ }^{1 *}$, Michela Tiboni ${ }^{2}$ \\ ${ }^{I}$ AIIT President, Full Professor of Transport Planning, University of Catania \\ ${ }^{2}$ AIIT Director of Studies and Research Center, Full Professor of Town and Regional Planning, \\ University of Brescia
}

\section{Editorial}

The special issue "Transport infrastructure and systems in a changing world: towards sustainable mobility planning" stems from the AIIT 2nd International Congress on Transport Infrastructure and Systems in a changing world (TIS ROMA 2019), which was held in Rome on $23^{\text {rd }}-24^{\text {th }}$ September 2019 (https://tisroma.aiit.it/). It was organized by AIIT, the Italian Association for Traffic and Transport Engineering, and hosted by ACI, Automobile Club d'Italia. The aim of the conference was to promote the knowledge of new trends of development of mobility systems and transport infrastructures "towards a more sustainable, reliable and smarter mobility".

TIS Roma 2019 aimed at providing a forum for discussion, interactions and exchange among researchers, scientists and engineers whose fields of interest concern transport and infrastructure engineering.

The opening ceremony of the congress, introduced by Matteo Ignaccolo, Chairman of the Conference and AIIT President, Full Professor of transport planning at the University of Catania (Italy), was characterized by a very interesting Opening Lecture by Christopher Zegras, Professor of Mobility and Urban Planning, MIT Boston (USA).

How can we enhance mobility's contribution to human development while reducing or eliminating the negative impacts that modern mobility systems impose on us, our ecosystems, and future generations? That is, how can we design and develop mobility systems that contribute to sustainable places?

Christopher Zegras's work focuses on three broad, inter-related areas critical to answering the previous question:

1) improving our understanding of the dynamic relationships between human behavior and the built, social, and natural environments;

2) devising and demonstrating new planning approaches, with the goal of producing more robust strategies for sustainability in the face of uncertainty; and

\footnotetext{
* Corresponding author: Matteo Ignaccolo (matteo.ignaccolo@unict.it)
} 
3) identifying viable pathways, through the complex institutional settings of the modern metropolis, to implement change.

$\mathrm{He}$ also explores the role of mobile communication and computation technologies as a new data source for estimating and validating models, as a tool for changing behaviors within the mobility system itself, and as a way to improve citizen engagement in planning processes.

Indeed his lecture for TIS Rome 2019 was about "Digitalization and the Future of Mobility".

The discussion of the lesson was made by Maurizio Tira, SIU President, Rector of the University of Brescia and Full Professor of Town and Regional Planning. Expert Member of the European Transport Safety Council since 1999, where he chaired two working parties on "Evaluation of road safety policies" and "Road safety policy integration", Maurizio Tira is an Expert member in two working parties of OECD-International Transport Forum about "Pedestrian safety, Urban space and health" and "Cycling safety".

Then the congress focused on important research topics related both to Transport Systems and Infrastructure. 135 papers were presented in 24 parallel sessions with participants from 33 countries.

All the papers were peer-reviewed before being approved for presentation at the conference. The majority of them was published in the volume "Transport Infrastructure and systems in a changing world. Towards a more sustainable, reliable and smarter mobility. TIS Roma 2019 Conference Proceedings, Edited by Matteo Ignaccolo and Michela Tiboni, Transportation Research Procedia, Elsevier, 2020", and 19 papers were selected to be part of two special issues of "European Transport $\backslash$ Trasporti Europei".

This second special issue focuses on safety in mobility, with 10 papers, which present either new methods or proofs of concept via relevant case studies, increasing the knowledge which pave the way for further research towards a safer mobility.

"Understanding how drivers are injured in rear-end collisions" is the topic of the paper by Essam Dabbour and Abdallah Badran. The paper investigates the temporal stability of the factors related to drivers' injuries in rear-end collisions (the most common type of collisions), and the research is based on utilizing logistic regression modelling to analyse all rear-end collisions that occurred in North Carolina from January 1, 2007 to December 31, 2013. The thesis of the authors is that understanding the temporal stability trends of the factors influencing how drivers are injured in rear-end collisions would help in evaluating the effectiveness of implementing different safety treatments so that researchers could understand whether any safety improvements, observed after applying a certain safety treatment, are attributed to the specific treatment or simply attributed to the temporal instability of the factors being addressed.

The findings of this research have the potential to help decision makers develop policies and countermeasures that improve roadway safety by focusing on risk factors that consistently increase the probability of injuries for drivers in rear-end collisions.

Francesco Saverio Capaldo and Daiva Žilionienè, in their paper "Stiffness of passenger cars: a class analysis", address the topic of methodologies that provide speed values starting from the deformations of the vehicles as a relationship to the structural stiffness coefficients. Some databases are available, concerning the coefficients obtained for a 
number of passenger cars and others concerning sister cars, which are used with a reasonable degree of approximation in forensic engineering works. In research work, different stiffness coefficients for passenger cars were analysed and grouped for displacement classes, length and pitch.

Alternative transport means (ATMs) such as e-bicycles, electric scooters, mobility scooters (for the elderly) and segways, are the topic of Victoria Gitelman, Anna Korchatov and Shalom Hakkert in the paper "Alternative transport means in city centers: exploring the levels of use, typical behaviours and risk factors".

The growing use of ATMs is accompanied by an increase in related injury and the study presented in the paper aimed to characterize the scope of ATM use in Israeli cities, their behaviours at typical urban locations and risk factors, and to consider solutions for safer ATMs integration into the urban space.

"Physiological and driving behaviour changes associated to different road intersections" is the paper by Natalia Distefano, Salvatore Leonardi, Giulia Pulvirenti, Richard Romano, Natasha Merat, Erwin Boer and Ellie Woolridge.

Assuming that the interaction between the human factor and the road environment are among the most common causes of road accidents, the paper deals with intersections, that are among the most complex road environments: their geometric and traffic characteristics weigh the driver workload, affecting the driving behaviour and consequently the risk of accident.

This study intends to contribute for a better understanding of the relationship between different types of intersection and the human factor, by collecting electrodermal activity continuously during a driving study and comparing the drivers' stress level for roundabouts and standard intersections.

Ronald Roberts, Laura Inzerillo and Gaetano Di Mino present the paper "Developing a framework for using Structure-from-Motion techniques for Road Distress applications", where they argue about how to quickly identify road pavement distresses, in order to find appropriate maintenance and rehabilitation strategies. Over the last few years there have been several attempts for new solutions and techniques and the paper illustrates the methodology Structure-from-Motion, which tries to recreate 3D distress models for identification and analysis, and presents a workflow of how it can be utilized to help optimize the pavement management system and their connections to different distress identification manuals worldwide.

"Safety Performance Functions for road intersections in the Friuli Venezia Giulia Region" by Nicola Baldo and Matteo Miani is a paper which aims to develop Safety Performance Functions (SPFs) of four different types of road intersections: unsignalized three-leg intersection, unsignalized four-leg intersection, signalized three-leg intersections, signalized four-leg intersection. The data on accidents and traffic volume of 28 intersections, which are under the jurisdiction of Friuli Venezia Giulia Strade S.p.A., were collected and analyzed, using a feed-forward artificial neural network.

Chiara Gruden, Tiziana Campisi, Antonino Canale, Matjaž Šraml and Giovanni Tesoriere aim to estimate the effects of induced pedestrian mobility on Mostar's Ottoman 
bridge in terms of safety, in the paper "The evaluation of the surrogate safety measures along a pedestrian confined ramp of an old bridge".

Starting from the geometrical evaluation of the old bridge of Mostar (BIH), the paper provides some ideas for evaluating the safety of pedestrians during the journey on the bridge, under different flow conditions. The analyses were carried out starting from an estimate of pedestrian flows from video monitoring. Safety was then assessed thanks to the calculation of surrogate measures, based on the trajectories of individuals, obtained through tracking tools. The evaluation of individual pedestrian trajectories and/or their interactions allows to estimate the movement variations through the study of parameters such as speed variation, pedestrian density and surrogate safety factors.

Microsimulation tools for evaluating road safety performance and allowing engineers to take appropriate countermeasures at specific points of the road network are the topic of the paper "Microsimulation and the Evaluation of Safety Levels in the Presence of Roadside Obstacles" by Vittorio Astarita, Demetrio Carmine Festa and Vincenzo Pasquale Giofrè.

The objective of this paper is to present a specific application of microsimulation software which is able to consider also potential conflicts with roadside objects. A specific microsimulation model add-on has been developed for the estimation of new road safety indicators that considers also potential crashes with roadside objects.

Giuseppe Cantisani, Giulia Del Serrone and Giorgia Di Biagio present a paper on “Results of Micro-Simulation Model for Exploring Drivers' Behavior on Acceleration Lanes", which examines drivers' behavior on acceleration lanes, close to the convergence between the main and the secondary traffic streams, by means of traffic microsimulations. Experimental data collected videotaping two acceleration lanes in Italy have been used to initially calibrate a simulation model and to validate it subsequently. The maneuvers have been implemented in the TransModeler traffic simulation package and several scenarios have been considered, changing the traffic composition and the speeds at which drivers enter the acceleration lane from time to time.

The topic of the introduction of the Building Information Modeling (BIM) approach in Civil Engineering practices, which allows a design optimization through both an improved control of all the components of a project and an increased efficiency in the collaboration between all professionals involved, is covered in the paper "BIM for infrastructure: an efficient process to achieve $4 D$ and $5 D$ digital dimensions" by Fabrizio D'Amico, Luca D'Ascanio, Maria Chiara De Falco, Chiara Ferrante, Davide Presta and Fabio Tosti.

The paper aims to propose a methodology for implementing an optimization dynamic model of time (4D) and costs (5D) across different project phases, introducing a dynamic model involving an optimization-oriented approach for both the quantity surveying and the definition of the design management timeline.

\section{Acknowledgements}

TIS ROMA 2019 chairs and the organizing committee would like to take this opportunity and express their gratitude to the scientific committee, to the contributors for 
their papers and presentations at the event, to the chairs of the sessions, and to the reviewers for their efforts and hard work for making the conference successful and for making possible the edition of these two special issues.

\section{References}

Ignaccolo, M., Tiboni, M., 2020. Transport Infrastructure and systems in a changing world. Towards a more sustainable, reliable and smarter mobility. TIS Roma 2019 Conference Proceedings, Transportation Research Procedia, Volume 45, https://doi.org/10.1016/j.trpro.2020.02.055

Tira, M., 2018. A safer mobility for a better town: The need of new concepts to promote walking and cycling. Town and Infrastructure Planning for Safety and Urban Quality Proceedings of the 23rd International Conference on Living and Walking in Cities, LWC 2017

Rossetti, S., Tiboni, M., Tira, M., 2014. Road safety in Italy: An assessment of the current situation and the priorities of intervention, Periodica Polytechnica Transportation Engineering

Yun, H.Y., Zegras, C., Palencia Arreola, D.H., 2019. "Digitalizing Walkability": Comparing Smartphone-Based and Web-Based Approaches to Measuring Neighborhood Walkability in Singapore. Journal of Urban Technology, https://doi.org/10.1080/10630732.2019.1625016

Zhao, F., Ghorpade, A., Pereira, F. C., Zegras, C., Ben-akiva, M., "Stop detection in smartphone based travel surveys", Transportation Research Procedia, Special issue on Transport Survey Methods: Embracing Behavioural and Technological Changes, Vol. 11, pages 218-226. 